\title{
Lições práticas do Manual de Judaísmo Carioca segundo Paulo Blank
}

Practical Lessons from the Manual of Carioca Judaism according to Paulo Blank

\author{
Nancy Rozenchan* \\ Universidade de São Paulo (USP) | São Paulo, Brasil \\ nrozench@usp.br
}

Resumo: Além de se propor a dar conta de uma história de vida ou de parte dela, o romance de formação precisa se acomodar a uma série de outras classificações que, por vezes, são acopladas a uma ou mais categorias particulares. Assim é o romance Mentch, a arte de criar um homem, de Paulo Blank, que se propõe a englobar na formação do pequeno carioca Paulo todas as virtudes do ser judeu no Rio de Janeiro nos anos 50 do século passado, assim como as vivências típicas da cidade de então. Passível de ser abordado sob outras categorias, como romance da maturidade travestido de roupagem de Bildungroman ou como obra típica da cultura judaica, a apreciação do romance se presta a desentranhar aspectos do instigante universo judaico do Rio de Janeiro daquela época.

Palavras-chave: Romance de Formação. Mentch. Paulo Blank.

Abstract: In addition to proposing to account for a life story or part of it, the formative novel needs to accommodate to a series of other classifications that are sometimes coupled to one or more particular categories. Such is the novel Mentch, a arte de criar um homem (Mentch, the art of creating a man), by Paulo Blank, which proposes to include in little Paulo's formation all the virtues of being a Jewish boy in Rio de Janeiro in last century's 50s, as well as the typical experiences of the city at that time. The book can be approached under other categories, as a novel of maturity dressed in Bildungroman clothing or as a typical work of Jewish culture. The appreciation of the novel lends itself to unraveling aspects of the instigating Jewish universe of Rio de Janeiro at that time.

Keywords: Formation Novel. Mentch. Paulo Blank.

Costuma-se considerar que um romance de formação traz de forma típica qualquer história de amadurecimento onde o personagem principal se confronta com a sua identidade através do processo de crescimento. Este tipo de definição genérica precisa, todavia, se adaptar a cada tipo de obra ao qual ela é atribuída e com grande probabilidade resultará em uma definição insuficiente para a qual se

\footnotetext{
* Professora Sênior de Língua e Literatura Hebraica da Universidade de São Paulo.
} 
sugere a anexação de diversas outras classificações que a contradigam ou não, ou que a ela acrescerão.

Para apreciar o romance Mentch, a arte de criar um homem, do psicanalista carioca Paulo Blank, incorre-se nestas dificuldades: elas abrangem desde a veracidade ou validação da catalogação como romance de formação até o seu deslocamento desta categoria para um segundo plano, já que vieses classificatórios diversos se sobrepõem a isso. Uma das hipóteses é que o livro, como romance de formação, pode ser contraposto pela ideia de que se trata de uma obra da análise da vida madura do autor/narrador, que procura se entender a partir dos anos da infância, ainda que o escopo da obra não abranja a fase adulta do personagem mas, sim, reflexões adultas de linhas do pensamento judaico. Talvez se possa lê-lo também como um tratado sobre o que é a identidade judaica de uma parcela muito específica do judeu carioca, ou mesmo, por uma leitura diversa, pensá-lo como uma típica obra pertinente à literatura judaica.

Considerando que nenhuma dessas possibilidades merece ser excluída, a rica gama oferecida por Mentch resulta em um privilégio para qualquer leitor com fôlego para tantas leituras possíveis.

Mentch - vocábulo ídiche, língua dos judeus do centro e leste europeus, significa "gente" e aqui é usado no sentido de ser uma pessoa decente. ${ }^{1} \mathrm{O}$ conceito do termo é amplo. No âmbito dos falantes do ídiche, ressoa como um lema a ser seguido, um objetivo a ser perseguido a todo custo pois é isto que define o judeu e o dignifica. A língua ídiche tem uma história e uma cultura específicas e uma carga emocional significativa das quais o conceito que está sendo abordado é um exemplo ímpar. Conhecedores da cultura judaica nesta língua sabem reconhecer esta conceituação nos principais expoentes de sua literatura desde o século XIX, de autores laicos como Mêndele Môicher Sforim, Shólem Alêichem e Itzchok Lêibush Péretz - os patriarcas modernos desta literatura - todos eles discerníveis de alguma forma na obra de Blank, e sabem reconhecê-la igualmente em pensadores antigos e contemporâneos, também em hebraico, como Rabi Nachman de Breslav ou Yeshayahu Leibovitz, nominalmente citados.

\footnotetext{
${ }^{1}$ O escritor Leo Rosten, de The Joys of Yiddish, define mentch como: "Someone to admire and emulate, someone of noble character. The key to being 'a real mensch' is nothing less than character, rectitude, dignity, a sense of what is right, responsible, decorous." (Alguém a ser admirado e imitado, alguém de caráter nobre. A chave para ser "um verdadeiro mentch" é nada menos que caráter, retidão, dignidade, um senso do que é certo, responsável, decoroso.). Citado em: KAWASAKI, 2006. (As traduções são de minha autoria).
} 
Ser mentch não é certamente um atributo particular judaico, porém a ênfase destacada por Blank faz com que se trate de avaliar como ele se coaduna com a identidade judaica.

O tema da identidade judaica, incluindo a questão de quem é judeu e o que constitui a "judeidade", é um dos assuntos mais controversos e contestáveis da história étnica e religiosa do povo judeu. Abrange desde como os judeus se imaginam até quem define o que significa ser judeu. Os próprios judeus conduziram desde sempre um diálogo interno, por vezes até irado, sobre como a judeidade deveria ou deve ser definida, como estas definições foram e são estabelecidas, instituídas, desafiadas e transformadas, assim como o que é normativo, o que é proclamação oficial, o que e por quem é imposto. Além disso, se ser judeu requer crença prática, religiosa e afiliação institucional formal.

O livro de Blank consubstancia, no que aparenta ser um romance de formação, todas essas buscas no que o pequeno narrador Paulo (segundo um dos seus nomes) deve ter em mente em sua vida: quaisquer que sejam os caminhos que lhe apontem e os muitos outros que se lhe apresentem, deve trilhar ou se ajustar a eles na condição de se tornar um ser ético, um mentch.

Isto se estende por prováveis cinco ou seis anos de sua existência na cidade do Rio de Janeiro dos anos 1950 até a partida para Israel e desembarque do navio Theodor Herzl no porto de Haifa. O período não especificado na obra é inferido pelas informações de seu aprendizado de leitura e provas de admissão ao antigo curso ginasial.

A narrativa, sempre em primeira pessoa, apresenta o narrador vivendo em uma vila modesta com a mãe e a avó, fugidas da Polônia, no núcleo urbano central genericamente conhecido como a então "Praça Onze", ${ }^{2}$ para onde confluíram muitos outros judeus que aportaram antes da II Guerra ou em seguida a ela. Para a vila, espaço semiaberto, convergiu a mescla habitacional da época: nacionalidades, cores, ocupações, pensamentos religiosos e políticos em suas variedades onde cada um procurou se encaixar em convivência tranquila. Se para a mãe e para a avó, que já tinham passado por muitas vicissitudes que incluíram perseguições antissemitas e o nazismo, o local e a ambientação precisam se constituir no porto seguro disponível, para o menino, cujo universo mal começa a se moldar, tornar-se o mentch apregoado pelas mulheres, viver neste ambiente

2 A princípio denominada de "Largo do Rocio Pequeno", a Praça Onze tornou-se, nas primeiras décadas do século $\mathrm{XX}$, um dos locais mais cosmopolitas da então Capital Federal, ao abrigar famílias de imigrantes recém desembarcados. As etnias mais populares no entorno da Praça Onze eram os negros (na maioria oriundos da Bahia), seguidos pelos judeus de várias procedências. Portugueses, espanhóis e italianos também eram numerosos ali. 


\section{Arquivo Maaravi}

é tão complicado quanto vivenciar o universo infantil em meio às ameaças ou afetos brasileiros que o cercam; assim ocorre também no ambiente escolar. Choques e confrontos alternam-se com as poucas sendas pacíficas que têm à disposição.

A mãe e a avó, com todo o envolvimento amoroso que lhe dispensam, procuram conduzi-lo, cada uma delas em separado, pelos seus caminhos, pavimentados segundo suas próprias convicções calcadas nos respectivos pontos de vista judaicos: a avó, seguindo a linha tradicional - para a Torá (Toire), o código da lei judaica, e ensinamentos correlatos e, com base neles, a vinculação com a Terra Santa, somados com uma certa dose de misticismo, bom elemento para instituir o mistério e o medo do desconhecido numa obra em que são benvindos para o crescimento do menino; a mãe, indicando a tendência libertadora do seu e dos outros povos, conforme estabelecidos pelo Bund, movimento trabalhista geral judaico da Polônia e partido socialista judaico daquele país. ${ }^{3}$ Ainda que a quantidade dos ensinamentos penda para o aspecto tradicional judaico, as menções socialistas do universo judaico são devidamente enfatizadas. A distribuição das mesmas no texto, sempre através das citações diretas ou indiretas do menino ávido por absorvê-las, aponta para a sua recepção equânime sem que ocorra um choque entre os ensinamentos. A narrativa relega ao leitor a tarefa de avaliar o papel de cada um. Para Paulo, a missão é somar e assimilar ensinamentos.

Ambas lhe instilam o que viveram no Velho Mundo, as tradições, segundo as visões de cada uma delas, e o que quase destruiu o seu povo. Ao menino cabe instruir-se ou discernir o que foi hostil a elas e que ele deve aprender a reconhecer para saber se defender e não se deixar ser pego em eventuais armadilhas semelhantes que possam se apresentar a ele.

Como ocorre em romances de formação, verifica-se que viver não lhe é fácil: aos inimigos nazistas e antissemitas da Europa fantasmagórica de suas protetoras e à grande empreitada de promover a salvação de todos os povos, cabe-lhe acrescentar o ambiente local que conflita com o seu legado cultural e emocional, mas onde precisa encontrar o espaço natural para o crescimento. Além das tensões múltiplas recebidas em casa - as do passado europeu e as das duas linhas judaicas antagônicas de vida, é com os meninos da vila que poderá brincar, viver a infância, é com a sua amizade que poderá contar mesmo quando as diferenças culturais os dispunham em campos adversários e constrangedores.

\footnotetext{
${ }^{3}$ Alguemainer idisher arbeter bund in Poiln (Elo Trabalhista Judaico Geral na Polônia) foi um partido socialista judaico que promoveu a autonomia social, cultural e política dos trabalhadores judeus, procurou combater o antissemitismo e se opôs em geral ao Sionismo.
} 


\section{Arquivo Maaravi}

Revista Digital de Estudos Judaicos da UFMG

ISSN: $1982-3053$

Desde a primeira linha do livro, ainda antes que se discirna qualquer traço identificador da trama, é o ambiente traiçoeiro carioca de então que vem à tona sem que o menino sequer já se possa dar conta de que deverá enfrentá-lo ou submeter-se a ele e sem ter ao menos a ideia de que esta é a vida que terá à sua frente. É o mulato maldoso, Jarcy, malandro, que, de forma gratuita e sorrateira, faz com que Paulo se fira. Já nas primeiras páginas, em ritmo frenético que se repetirá em cada narrativa de enfrentamento de Paulo com elementos hostis, as ações e reações desencadeadas por este acontecimento são relatadas de um fôlego só, servirão para expor espanto e medo do menino, seu posterior pasmo pelo ocorrido, assim como o caráter e sentimentos de todos os envolvidos: o malandro faz com que Paulo tropece e caia, a mãe e a avó acodem ao choro, o agressor lança a sua declaração antissemita, nazista, a mãe revida e bate no agressor, todos da vila assistem à sua queda, a corrida ao pronto-socorro, a ajuda do taxista solidário, as versões do assalto e do revide repercutem, o agressor volta para tirar satisfação, é descartado com um golpe de tesoura da mãe.

Na mesma rapidez narrativa como a utilizada na descrição dos eventos da primeira cena, vão sendo incluídos os elementos condutores das duas mentoras: a ação prática da mãe e a espiritual da avó. Já aí se toma conhecimento que, diante de todos os males e perigos, é a invocação do riboinesheloilem, ${ }^{4}$ versão idichizada do hebraico ribonô shel olam - Senhor do Universo - que deve viger.

Na estrutura do universo infantil, Paulo, o pivô da história, tem, por seu lado, os seus eus imaginários, Paulo Rowilsky e Paulo Patrucha (suas versões judaica tradicional e judaica combatente?), prontos a ajudá-lo a confrontar-se com o medo e o perigo, para avaliar a situação, e com eles confabula pelo espelho da penteadeira; eles o conduzem, devidamente amparado, para o pátio da escola para se apresentar como figura de destaque do acontecido. Todavia, esse recurso estrutural apresentado logo no início da obra é a seguir deixado de lado. Mais do que aos dois Paulos, o protagonista passa a se reportar aos personagens dos ricos repertórios da cultura judaica, conforme aprendidos da mãe e da avó, que proporcionam farto material de heroísmo e modelos vencedores.

Se do relacionamento com os meninos e os eventos da rua brotam, além da amizade, medos concretos do pequeno judeu carioca como o de ser batizado à força, ou o que pode suceder quando há queima do boneco de Judas no sábado de Aleluia, da dicotomia do pensamento apresentada pelas duas mulheres que o amam brota o receio de, devido à frágil idade, não podendo negociar a mescla benéfica do que elas lhe pregam, decepcioná-las e não conseguir chegar à grande

\footnotetext{
${ }^{4}$ Todos os termos referentes à cultura judaica, ainda que em sua maioria sejam vocábulos hebraicos, são registrados no livro na forma da pronúncia idichizada.
} 


\section{Arquivo Maaravi}

virtude de se tornar gente, de se tornar alguém, algo cujo alcance ele ainda não tem capacidade de apreender.

Todos estes embates - elementos que compõem a complicação e ansiedade características do romance de formação - também não se resolvem na escola religiosa que ele frequenta, uma vez que ali surgem novos choques: as duas linhas condutoras da casa, que conviviam em paralelo, com poucos atritos, não se afinam com o que o mestre estabelece. Sua condição familiar e socioeconômica, bastante diversa da de alguns dos seus colegas, também é motivo para grandes antagonismos e batalhas. Traduzidos em aventuras e batalhas, na escola e na rua, apesar da sua fragilidade, o menino se salva, sempre ajudado por alguém. Cada confronto resulta em feridas e aprendizados para a sobrevivência presente e futura.

Nos anos 1950, alunos das escolas judaicas brasileiras não escapavam das engraçadas ou atemorizantes epopeias lidas em alguns contos ídiches, nesta língua ou em hebraico, dos três autores mencionados anteriormente, ensinados por seu caráter formador e educador intenso: as estripulias do órfão Motl, de Sholem Aleichem, ${ }^{5}$ os judeuzinhos vermelhos ${ }^{6}$ que precisavam vencer o turbulento Rio Sambation para atingir a Terra Santa, de Mêndele, ou como chegar a um lugar mais alto que o céu pela difícil prática das boas ações como sugerido por Péretz. ${ }^{7} \mathrm{Na}$ vida do menino, essas empreitadas, apenas insinuadas no texto, fundem-se com as que os meninos daquela época sorviam da ambientação local. Se, anos depois, na música "João e Maria", Chico Buarque iria cantar "agora eu era o herói, e o meu cavalo só falava inglês", Paulo também pode emparelhar os Moishe (Moisés) e Ioshie (Josué) e outras figuras bíblicas heroicas instilados pela avó tanto às imagens das figurinhas colecionadas como com quaisquer outros personagens que estavam então em voga. Todos eles podem vir em seu auxílio no momento necessário.

Os nomes, entidades, personagens, heróis e feitos pregados pela mãe e principalmente pela avó são numerosos. Assim como os já citados riboinesheloilem e Toire, quase todos são mencionados pela avó na forma de pronúncia idichizada. Esta opção, ao invés do uso da língua hebraica original dos mesmos, induz a um estranhamento talvez imperceptível aos que desconhecem a língua, um estranhamento enriquecedor. Referindo-se ao uso da língua, Benjamin Harshav afirma: "what marks it as a different medium are special features interspersed by its

\footnotetext{
${ }^{5}$ Da obra: Motl, filho do chantre Pêissach.

${ }^{6}$ Figuras folclóricas destacadas em Viagens de Benjamin III.

${ }^{7}$ Dos contos: "E talvez mais alto" e "Bontsha, o silencioso".
} 
users". ${ }^{8}$ Para esse autor, a característica do ídiche, pensado no seu uso mais popular, é que ele possui

A second level of language, ... that is, the "language" of communication accepted by the speakers of a community ... It comprises a whole network of signals, rules of conversation, encapsulated formulas and labels, allusions to codified and richly connotative life situations. ${ }^{9}$

Riboinesheloilem, por exemplo, não é apenas referência a Deus, vocábulo que não sugere o mesmo distanciamento e respeito que Senhor, Dono do Universo, em português; riboinesheloilem é mais atemorizante para o menino, muito mais do que o quase abstrato "Deus", talvez também mais protetor. A expressão emotiva das palavras grafadas na forma ídiche pode estar propondo um universo em que há um pai (lembrando que na trama não há um pai de Paulo) que cuida, ainda que severo. Assim se dá também com a palavra mentch e outras trazidas naquela língua. Mentch, como já se viu, não é simplesmente gente, pessoa.

No decorrer da trama, os modelos éticos a serem seguidos ampliam-se e ganham a companhia de outros que passam aos poucos a ser abrangidos como os indicados para nortear as complexidades de uma vida adulta; ampliam o rol de atributos necessários para uma criança se tornar mentch, mesmo que escapem à sua compreensão. Alguns são trazidos repetidamente.

O menino Paulo ecoa os princípios que nortearam figuras como o fundador do movimento chassídico, o Baal Shem Toiv, ${ }^{10}$ o auto-apregoado messias Sabetai $\mathrm{Zvi}^{11}$ conceitos de alma errante do Dibbek ${ }^{12}$ e do ser artificial mítico consubstanciado no Goilem, ${ }^{13}$ líderes de pensamentos diversos como o mentor chassídico Nachman de Breslav ${ }^{14}$ e o cientista e figura pública israelense contemporânea Yeshayahu Leibovitz, ${ }^{15}$ muitos dos quais não povoaram $\mathrm{O}$ universo infantil do período retratado e, em parte, nem de adultos de então, como é o caso de Leibovitz, vivo naquela época, pois não eram ainda muito

\footnotetext{
8 "O que o marca como um meio diferente são características especiais intercaladas por seus usuários." (HARSHAV, 1994, p. 144).

9 “Um segundo nível de linguagem, isto é, a 'linguagem' de comunicação aceita pelos falantes de uma comunidade [...] compreende toda uma rede de sinais, regras de conversação, fórmulas e rótulos encapsulados, alusões a situações de vida codificadas e ricamente conotativas." (HARSHAV, 1994, p. 144, 145).

10 BLANK, 2016, p. 41.

${ }^{11}$ BLANK, 2016, p. 99.

12 BLANK, 2016, p. 120.

${ }^{13}$ BLANK, 2016, p. 16.

${ }^{14}$ BLANK, 2016, p. 198.

${ }^{15}$ BLANK, 2016, p. 186.
} 


\section{Arquivo Maaravi}

popularizados ou conhecidos no Brasil. O personagem ficcional Iosel Rakover ${ }^{16}$ ou o líder do Levante do Gueto de Varsóvia Mordechai Anilevitsh, ${ }^{17}$ do repertório da mãe, também compõem o elenco dos exemplos para se criar um mentch. Tanto quanto a Toire da avó, da qual ela sempre extrai o texto apropriado para ajudar a ultrapassar as dificuldades do momento, a mística, com o Sêfer Yetsirá e suas práticas, os atos denotadores de antigas superstições, os causos, hinos e bandeiras revolucionárias da mãe cumprem o mister de criar Paulo, de chegar ao propósito apregoado. Às figuras do Dibbek e do Goilem subjazem conceitos de busca do reparo ou da correção de um indivíduo ou comunidade; o judaísmo ante as religiões que dele derivaram está embutido na menção da "luta dos filhos da luz contra os filhos das trevas" - referência explícita aos Manuscritos do Mar Morto encontrados em 1947.

Transposto para o nível escolar infantil, o muro que separa o colégio católico Menino Jesus e a escola judaica religiosa Sábios de Tsion de Paulo expõe a pequena, mas intransponível distância entre polos tão diversos; o aspecto jocoso das aventuras envolvendo as duas casas de ensino atenua os temores nas cenas narradas. Mesmo a ironia envolvendo os nomes das duas instituições - a sabedoria de um, pequeno, ante toda a sabedoria das gerações antecessoras contribui para o estabelecimento de parâmetros identitários.

Levando em conta este vasto repertório, Mentch, de Blank, é pura literatura judaica, conforme propõe Hana Wirth-Nesher: "Some have suggested that Jewish literature is marked by a profound consciousness of Jewish history ... in Robert Alter's terms, ... drawing upon literary traditions that are recognizably Jewish" ${ }^{18}$

Todavia, ainda segundo ela, considerar uma obra como sendo literatura judaica depende igualmente do leitor e das circunstâncias da recepção do texto: "Its characterization as Jewish will depend upon the reader and all the circumstances of its reception". ${ }^{19} \mathrm{O}$ leitor que reconhece que um personagem ou tema tem vinculação com outros que os antecederam estará ciente da conexão de uma obra à tradição literária judaica.

Além da menção da Toire que oferece personagens e modelos sem fim, delineiase, na obra de Blank, já desde o início, o pensamento de Rabi Nachman. Na cena inicial da agressão pelo mulato, depois de derrubado, o menino é atendido no

\footnotetext{
${ }^{16}$ BLANK, 2016, p. 106.

17 BLANK, 2016, p. 139.

18 “[...] alguns sugeriram que a literatura judaica é marcada por uma profunda consciência da história judaica ... ou, nos termos de Robert Alter [...] basear-se em tradições literárias que são reconhecidamente judaicas". (WIRTH-NESHER, 1994, p. 5). 19 "Sua caracterização como judaica dependerá do leitor e de todas as circunstâncias de sua recepção." (WIRTH-NESHER, 1994, p. 5).
} 


\section{Arquivo Maaravi}

pronto-socorro; a mãe mordia o lábio enquanto costuravam o corte do menino. Sofrimento próprio e da mãe trazem à lembrança o ensinamento desta naquele momento: "Ela vivia repetindo que a vida era uma ponte longa e estreita que tínhamos de atravessar sem nos desesperar". ${ }^{20}$

O (hoje) bastante conhecido, repetido e popular ensinamento do mestre chassídico de Breslav, inclusive em forma cantada, "col haolam culô guésher tsar meód vehaikar lo lefahed clal" (o mundo todo é uma ponte muito estreita e o que importa é não temer em absoluto), que visa como os seus demais pensamentos a levar as pessoas a desenvolverem para si um relacionamento forte e satisfatório com Deus, é um dos que mais intrigam o menino que faz repetidas tentativas de dissecção do mesmo para tentar entender o seu propósito; pelo número de repetições, por acentuar um caminho mais específico que a citação genérica da Toire, torna-se um dos principais lemas do comportamento de Paulo e do próprio judaísmo. "Mais de uma vez perguntei qual era o propósito de viver atravessando uma ponte sem chegar a lugar nenhum". A mãe sorria, dizendo que o importante era seguir em frente" ${ }^{21}$ Este tema, sempre abordado de forma breve, ressoa no decorrer do texto em outras pontes oriundas da imaginação do personagem; pode ser até uma materializada ponte sobre o Amazonas.

Chegar à perfeição é um projeto de vida. Toire, riboinesheloilem, atravessar a ponte estreita ainda não serão bastante suficientes para conduzir o projeto de vida, há mais a ser vencido. Quando a vida do personagem toma novo rumo com a ida a Israel nas últimas páginas do romance, em compasso com as opções ditadas pela atividade psicanalítica cumprida pelo autor, a introdução fugidia de dois novos elementos se insinua como a tentativa de resumir de que modo, enfim, apesar das dificuldades, o objetivo a ser atingido pode, talvez, ser encarado: o bahershen da avó (dominar-se, se controlar), o aprendizado do autocontrole, "passou a ser uma palavra que voltaria a usar sempre que precisava retomar o controle do seu destino". ${ }^{22}$ As certezas místicas da debilitada avó dificilmente poderiam se cumprir. Quanto à mãe, são as incertezas que complicam a sua trajetória: ir para Eretzisruel (Terra de Israel), ficar na Europa, ou dirigir-se para Birobidjan, o sonhado paraíso socialista judaico? Sempre haveria alguém a lhe remexer as antigas caraminholas da cabeça.

Com o bahershen e com os menies ${ }^{23}$ (meniot, em hebraico) - os entraves -, completase um ensinamento hassídico fundamental do Rabino Nachman. Quando se está a ponto de promover um reparo (um tikun) na vida, o Sitra Achra surge e interpõe

\footnotetext{
${ }^{20}$ BLANK, 2016, p. 13.

${ }^{21}$ BLANK, 2016, p. 14.

${ }^{22}$ BLANK, 2016, p. 171.

${ }^{23}$ BLANK, 2016, p. 173.
} 


\section{Arquivo Maaravi}

menies, empecilhos. Sitra Achra - o outro lado, em aramaico, é a expressão cabalística que serve como um título geral para todas as forças da impureza e do mal. São dores do legado do Livre Arbítrio. A se seguir a lógica hassídica dos menies, quanto mais se multiplicam os entraves, maior será a salvação. Quem tem forças para isto? Para o autor Paulo, o menino Paulo aparentemente assimilou os caminhos. Quanto ao próprio autor, só ele pode informar. Mas, já que estão incluídos no livro, perto do final, passam a ser as opções abertas que todos os Paulos devem antever.

O inventário judaico do livro é imenso e usado com maestria, refletindo o universo infantil e o adulto. Com Márcio Seligmann-Silva, comentando o tema do inventário segundo Mary Carruthers, é válido considerar que

Sem os saberes depositados e inventariados na nossa mente, não poderíamos criar ou inventar. A noção de inventário, por sua vez, já traz em si a questão de uma topografia do saber acumulado. $\mathrm{O}$ conhecimento era necessariamente articulado à nossa capacidade de montar uma espécie de "biblioteca privada" dentro de nós. ${ }^{24}$

Paulo Blank teve a força de juntar tudo isso, mastigar, dispor na medida que o seu talento e fantasia o inspiraram. Obra de literatura judaica e/ou romance de formação de um judeu carioca com a qual deleite e aprendizado caminham passo a passo.

\section{Referências}

BLANK, Paulo. Mentch, a arte de criar um homem. Rio de Janeiro: 7Letras, 2016.

BUARQUE, Chico; SIVUCA. João e Maria, 1976.

HARSHAV, Benjamin. The Semiotics of Yiddish Communication. In: WIRTHNESHER, Hana. What is Jewish Literature? Philadelphia, Jerusalem: The Jewish Publication Society, 1994.

ROSTEN, Leo. The Joys of Yiddish. Nova York, McGraw-Hill, 1968. In: KAWASAKI, Guy. How to Be a Mensch. How to change the world. 11 fev. 2006. Disponível em: <https://web.archive.org/web/20081019024918/http://blog.guykawasaki.com/2006/02/h ow_to_be_a_men.html>. Acesso em: 20 ago. 2018.

SELIGMANN-SILVA, Márcio. Palavras introdutórias. Remate de males. Dossiê Literatura como uma arte da memória. Campinas, n. 26, jan.-jun. 2006.

\footnotetext{
${ }^{24}$ SELIGMANN-SILVA, 2006, p. 7.
} 


\section{Arquivo Maaravi}

2 Revista Digital de Estudos Judaicos da UFMG

WIRTH-NESHER, Hana. What is Jewish Literature? Philadelphia, Jerusalem: The Jewish Publication Society, 1994.

Recebido em: 20/09/2019.

Aprovado em: 20/10/2019. 